\title{
Conflitos Éticos e Judiciais no Emprego dos Stents Farmacológicos no Brasil. Análise das Principais Controvérsias para Incorporação dessa Tecnologia nos Sistemas de Saúde Público e Privado no País
}

\author{
Marcelo Antônio Cartaxo Queiroga Lopes'1, Marcelo Antonio Cartaxo Queiroga Lopes Filho², \\ Luiz Antonio Gubolino ${ }^{3}$, Luiz Alberto Mattos ${ }^{4}$, José Antonio Marin-Neto ${ }^{5}$
}

\section{RESUMO}

Em 2002, os stents farmacológicos foram aprovados pela Agência Nacional de Vigilância Sanitária (ANVISA). Desde então, sua utilização regular no Brasil tem sido restringida, restrição essa alegadamente motivada pelo custo, considerado elevado pelos agentes financiadores da saúde no País. Tal fato tem desencadeado série extensa de conflitos éticos e judiciais, envolvendo pacientes, médicos e operadoras e provedores de planos de saúde, que, via de regra, desaguaram em demandas diante do Poder Judiciário. Neste artigo, discutiremos as várias especificidades éticas e legais envolvidas, à luz do judiciário pátrio, correlacionadas com a incorporação dos stents farmacológicos no Brasil. Para embasar a discussão, procedeu-se a uma pesquisa das jurisprudências acerca do tema nos principais tribunais do País.

DESCRITORES: Angioplastia transluminal percutânea coronária. Stents farmacológicos. Próteses e implantes. Poder Judiciário. Ética.

\footnotetext{
1 Cardiocenter - Hospital Santa Paula - João Pessoa, PB, Brasil. 2 Faculdade de Direito da Universidade de São Paulo (USP) - São Paulo, SP, Brasil/Bolsista do Deutscher Akademischer Austausch Dienst - DAAD (Serviço Alemão de Intercâmbio Acadêmico) Universidade de Munique (Ludwig-Maximilians-Universität München) - Munique, Alemanha.

${ }^{3}$ Incorpi - Instituto do Coração de Piracicaba, Hospital Fornecedores de Cana - Piracicaba, SP, Brasil.

${ }^{4}$ Instituto Dante Pazzanese de Cardiologia - São Paulo, SP, Brasil. ${ }^{5}$ Divisão de Cardiologia - Hospital das Clínicas da Faculdade de Medicina de Ribeirão Preto (USP) - Ribeirão Preto, SP, Brasil. Correspondência: Marcelo Antônio Cartaxo Queiroga Lopes. Av. Max Zagel, 91 - Cabedelo, PB, Brasil - CEP 58310-000

E-mail: mqueiroga@terra.com.br

Recebido em: 6/2/2009 • Aceito em: 17/3/2009
}

\section{ABSTRACT}

Ethical and Legal Conflicts in the Use of Drug Eluting Stents in Brazil. Analysis of the Major Controversies for the Adoption of this Technology in Public and Private Health Care Systems in this Country

Drug eluting stents were approved by the Agência Nacional de Vigilância Sanitária (ANVISA) in 2002. Since then, their regular use in Brazil has been restricted, allegedly due to their cost, which is considered high by national health funding agencies. This has led to an extensive series of ethical and legal conflicts, involving patients, physicians and health care plans and providers, which commonly result in lawsuits in the National Judiciary System. In this article, we will discuss the various ethical and legal aspects involved in the conflicts, regarding the incorporation of drug eluting stents in Brazil. A research of former court decisions on this subject was carried out to support this discussion.

DESCRIPTORS: Angioplasty, transluminal, percutaneous coronary. Drug-eluting stents. Prostheses and implants. Judicial Power. Ethics.

E 1977, Andreas Gruentzig introduziu a técnica de angioplastia coronária por via transluminal ${ }^{1}$, em Zurique, Suíça, inaugurando a era das intervenções percutâneas como opção para o tratamento da doença arterial coronária (DAC). O notável desenvolvimento conseguido com o aperfeiçoamento dos materiais disponíveis e o incremento das habilidades técnicas pelos cardiologistas intervencionistas permitiram a difusão crescente do método em todo o mundo, notadamente após a introdução dos stents coronários ${ }^{2}$. Com isso, tornou-se, na atualidade, a forma mais frequentemente utilizada para revascularização do miocárdio.

A despeito dos benefícios incontestes verificados com o emprego das intervenções coronárias percutâneas 
(ICP), especialmente relativos a seu caráter menos invasivo em cotejo ao método cirúrgico de revascularização miocárdica, há comumente a possibilidade de reestenose no local da lesão tratada ${ }^{3,4}$. Esse é o principal paraefeito relacionado à técnica, que ocorre quase exclusivamente ainda no primeiro ano após o procedimento. A reestenose é fenômeno ubíquo, pela reação cicatricial local excessiva, e consequente à injúria endotelial promovida pelos instrumentais de dilatação percutânea. A proliferação de células musculares lisas causa hiperplasia intimal e, quando abusiva, pode ocasionar a reobstrução do vaso coronário previamente tratado.

Para minimizar a incidência de reestenose após ICP, foram testados inúmeros métodos e técnicas de efeito físico ou farmacológico, os quais, sistematicamente, não rendundaram em resultados adequados. Exceção marcante a essa constatação foi providenciada pelos stents farmacológicos, que, pela primeira vez e de forma muito nítida, resultaram em controle eficaz da reestenose coronária, nos vários contextos cientificamente estudados ${ }^{5}$. Deve-se assinalar que essa complicação tardia, a reestenose, compromete o resultado a longo prazo da ICP, ocasionando indiscutível prejuízo na qualidade de vida dos portadores de DAC tratados por meio de ICP. No Brasil, desde maio de 2002, a Agência Nacional de Vigilância Sanitária (ANVISA) autorizou o emprego dos stents farmacológicos para tratamento percutâneo da DAC. Assim, viabilizouse legalmente o uso regular desses dispositivos, pois apenas com a autorização das autoridades regulatórias sanitárias é possível aplicar ou comercializar um dispositivo ou fármaco em território nacional. Cumpriuse, assim, a primeira etapa necessária ao processo de incorporação de novas tecnologias. A aceitação do reembolso por parte dos agentes financiadores da saúde, públicos e privados, contudo, persiste como passo fundamental a ser concretizado.

No que tange à incorporação das novas tecnologias em saúde pelos sistemas sociais provedores de assistência médica, usualmente o nó górdio a ser desatado consiste no elevado custo dessas tecnologias. Isso, a priori, vincula-se à necessidade de recuperar os maciços investimentos associados ao desenvolvimento das pesquisas clínicas que culminaram na disponibilização desses avanços tecnológicos. Tal premissa não é apanágio da área médica; verifica-se em quase todas as esferas onde se emprega tecnologia de ponta. No entanto, em se tratando de saúde - importante bem, tutelado, em maior ou menor grau, pelo Estado -, há extenso arcabouço legal, constitucional e mesmo infraconstitucional, que tende a assegurar as condições necessárias para acesso universal e igualitário da população aos novos recursos tecnológicos. Dessa forma, a discussão de questões de ordem econômica, apesar de pertinente, torna-se secundária ante o real dever de atender aos reclames legítimos da sociedade.
O tema assume especial relevo quando se considera que existem formas alternativas para o tratamento da DAC, uma vez determinada clinicamente a indicação formal de revascularização do miocárdio, podendo-se optar por uma técnica cirúrgica ou intervencionista $^{6,7}$. Nesta segunda opção, pode se tornar inafastável, no contexto atual, o dilema entre o uso de stents convencionais e o de stents farmacológicos. Nesse sentido, o papel do médico merece realce, pois sua decisão deve nortear a conduta a ser seguida, e a relação de custo-efetividade desses procedimentos também deve ser sopesada, sobretudo no contexto mais amplo da saúde pública. Neste ensaio, faremos uma análise detida dos principais conflitos éticos e judiciais existentes no Brasil, relativos ao emprego dos stents farmacológicos.

\section{O EMPREGO DOS STENTS FARMACOLÓGICOS, AS OPERADORAS DE PLANOS DE SAÚDE, O CÓDIGO DE ÉTICA MÉDICA E A LEGISLAÇÃO BRASILEIRA}

O advento dos stents farmacológicos aumentou o perfil de eficácia das $\mathrm{ICP}^{8}$, possibilitando seu emprego em situações clínicas não consideradas previamente. Ampliou-se, por conseguinte, o cenário de sua aplicação em cardiologia ${ }^{9}$, constituindo-se em alternativa segura e eficaz no tratamento da DAC, notadamente, por reduzir, de forma significativa, a frequência de ocorrência do fenômeno da reestenose. A questão dependente do alto valor monetário agregado desses dispositivos, no entanto, tem restringido a aplicação dessa tecnologia aos pacientes tratados com ICP no Brasil ${ }^{10,11}$.

A discussão acerca dos contextos clínicos em que os stents farmacológicos deveriam ser empregados não é nosso objetivo. Trataremos do tema, admitindo-se o cenário de uma indicação médica consensual para o uso do dispositivo. Nessa conjuntura, as operadoras de planos de saúde adotam em geral duas condutas: a autorização ou a negativa. Na segunda situação, quase sempre, alega-se a inexistência de cobertura contratual para próteses ou se contesta sua indicação, mesmo diante do respaldo por diretrizes societárias, com frequência argumentando-se com a existência de desacordo com protocolos internos de condutas médicas. Acrescente-se, ainda, que, mesmo diante de autorização, as operadoras podem assumir posturas restritivas ao tentar impor o uso de determinadas marcas comerciais dos stents farmacológicos, em divergência com a requisição médica do dispositivo indicado para aquele contexto configurado pela condição mórbida do paciente e as características inerentes do stent farmacológico.

Desde 1998, no Brasil, as operadoras de planos de saúde estão submetidas a um ordenamento jurídico próprio, a Lei 9.656, sem prejuízo do cumprimento 

para Incorporação dessa Tecnologia nos Sistemas de Saúde Público e Privado no País. Rev Bras Cardiol Invas. 2009;17(1):117-32.

da legislação mais ampla e específica que rege sua atividade. Adstringem-se, igualmente, à Lei 8.078, que trata dos direitos do consumidor, acrescida das normatizações impostas a seus dirigentes médicos pelo Conselho Federal de Medicina (CFM). Nota-se que o inadimplemento de quaisquer dos injuntivos legais mencionados pode ensejar litígios judiciais. Ressaltese que a Lei 9.656 instituiu a Agência Nacional de Saúde Suplementar (ANS), que tem a incumbência explícita de regulamentar o setor.

Cumpre frisar que o emprego dos stents farmacológicos em todo o território nacional se encontra respaldado no artigo 10 da retrocitada lei, a qual, ao criar o plano de referência com cobertura integral dos tratamentos das enfermidades listadas na Classificação Estatística Internacional de Doenças e Problemas Relacionados com a Saúde da Organização Mundial da Saúde, excluiu, tão-somente, mediante o enunciado do inciso VII, o fornecimento de próteses, órteses e seus acessórios não ligados ao ato cirúrgico. Merece ainda ênfase a coexistência de planos pactuados antes da legislação de 1998, em que vigora o disposto no contrato de adesão entre as partes, fato que possibilitaria a negativa de eventuais coberturas.

Destarte, em qualquer situação em que se vislumbre restrição ao ato médico - salvo em flagrante desfavor do paciente, nos procedimentos experimentais realizados fora do âmbito da pesquisa clínica ou proibidos pela legislação - manifestam-se ofensas à autonomia profissional, um dos pilares que fundamentam o exercício da medicina. O Código de Ética Médica estabelece, em seus Princípios Fundamentais, que o médico não pode, em qualquer circunstância ou sob qualquer pretexto, renunciar a sua liberdade profissional, devendo evitar que quaisquer restrições ou imposições possam prejudicar a eficácia e a correção de seu trabalho. Tal assertiva é reafirmada em seu artigo 21: "É direito do médico: Indicar o procedimento adequado ao paciente, observadas as práticas reconhecidamente aceitas e respeitando as normas legais vigentes no País".

Discorrendo acerca do tema, pontifica o desembargador Miguel Kfouri Neto ${ }^{12}$ : "O único limite que deve ser posto a essa liberdade é aquele que deriva das regras unanimemente aceitas e seguras da ciência médica, isto é, da lex artis - porque a nenhum médico é dado afastar-se da estrada que nenhum risco representa para o paciente, a fim de enveredar por outra, desconhecida e perigosa". Em acréscimo, também nos ensina: "Diante de situações duvidosas - ainda não definitivamente sedimentadas na medicina -, doutrina e jurisprudência concedem ao médico substancial liberdade de agir, sem que sua escolha possa ser questionada. Deixar uma boa margem de iniciativa e uma consistente liberdade e determinar a escolha do tratamento significa favorecer o progresso científico e valorizar a qualidade dos propósitos e inteligências médicas".
Com efeito, ressalte-se que não se deve confundir autonomia do médico com salvo-conduto para atuar sem qualquer limite ou restrição. Tal aspecto transparece cristalino ao subordinar-se a indicação de determinado procedimento às práticas reconhecidamente aceitas, em sintonia com o entendimento defendido pelo insigne jurista. Dessa forma, poderíamos aludir como referência norteadora dos parâmetros aceitáveis para indicação de stents farmacológicos as Diretrizes da Sociedade Brasileira de Cardiologia - Intervenção Coronária Percutânea e Métodos Adjuntos Diagnósticos em Cardiologia Intervencionista (II Edição) ${ }^{13}$. No citado documento societário, está elencada a opinião consensual dos especialistas na área no Brasil, calcada no nível mais elevado e disponível no contexto da Medicina Embasada em Evidência.

Na visão do CFM, as diretrizes médicas conciliam informações da área médica a fim de padronizar condutas que auxiliem o raciocínio e a tomada de decisão do médico. Isso usualmente se faz mediante elaboração de recomendações apresentadas com graus variáveis de indicação, por sua vez lastreadas em níveis diversificados e ordenados de evidência científica. Assim sendo, as diretrizes essencialmente preservam a autonomia dos médicos, para condutas personalizadas e individualizadas de acordo com o contexto em que atuam, e constituem, portanto, uma referência éticocientífica de limites da prática da medicina.

Desde o mais antigo diploma ético da medicina que a história preservou - o Juramento de Hipócrates -, a responsabilidade médica enquadra-se no quadrilátero cujos vértices são: os deveres de cuidados, a abstenção de abusos, o aconselhamento ou informação, e o sigilo profissional. Ao discorrer sobre o uso dos stents farmacológicos, três dessas obrigações ficam patentes: o dever de cuidado, que se centra na exigência de o médico ter de empregar o melhor da medicina em favor do paciente; o dever de aconseIhamento ou informação, o qual contempla a necessidade de explanar, de forma clara e acessível, acerca das variedades e implicações do procedimento; e, finalmente, o dever de abstenção do abuso, perceptível no caso do emprego desses dispositivos em situações sem previsão no bulário e tampouco em diretrizes societárias.

Por outro lado, é necessário realçar que existe variada série de situações em que se verificam indicações limítrofes ou inadequadas, as quais podem e devem ser questionadas nas searas competentes, pois as operadoras de planos de saúde assumem responsabilidade civil objetiva, como litisconsorte em relação a seus usuários, devendo oferecer-lhes assistência médica adequada. Em adição, deve-se observar o disposto no artigo 42 do Código de Ética Médica, no qual se veda ao médico a prática ou indicação de atos médicos desnecessários ou proibidos pela legislação do País. A atuação de uma auditoria médica atenta, 
consequentemente, pode coibir determinadas práticas em desfavor do paciente. Nesse sentido, merece destaque a Resolução do CFM no 1614/2001, que dispõe sobre auditoria médica, conferindo uma série de prerrogativas ao médico auditor no cumprimento da sua função. No entanto, em seu artigo $8^{\circ}$, tal ato normativo veda ao auditor autorizar, vetar, bem como modificar procedimentos propedêuticos e/ou terapêuticos solicitados, salvo em situação de indiscutível conveniência para o paciente, devendo, neste caso, fundamentar e comunicar, por escrito, o fato ao médico assistente do mesmo.

A despeito da discussão ética e legal que permeia esse tema, não se pode obscurecer que o principal aspecto envolvido nessa questão prende-se a razões meramente de cunho econômico, pois a terapêutica com os stents farmacológicos tem valor elevado e muitas vezes pode superar o custo global do tratamento cirúrgico, mesmo diante do período mais prolongado de internação e do caráter mais invasivo da cirurgia de revascularização do miocárdio. Seguramente, é lícito e defensável que as operadoras procurem controlar seus custos, visando à sua estabilidade econômica, mas não se pode, a esse pretexto, restringir a atuação legítima dos médicos, os interesses dos pacientes e o progresso da medicina.

\section{SOBRE AS CRÍTICAS À FUNDAMENTAÇÃO CIENTÍFICA DO USO DE STENTS FARMACOLÓGICOS}

Uma análise mais circunstanciada e detalhada da base científica para o emprego dos stents farmacológicos extrapolaria o escopo deste artigo. No entanto, uma das objeções mais frequentes ao emprego dos stents farmacológicos prende-se ao fato de que, em estudos controlados e aleatorizados, não se tenha demonstrado que, em comparação a seus congêneres, os stents não-farmacológicos, os stents farmacológicos não promovam redução da ocorrência isolada ou combinada dos desfechos clínicos mais graves que espreitam pacientes com DAC, infarto do miocárdio e óbito ${ }^{14}$. Entretanto, estudos metanalíticos mais recentes, congregando 37 desses ensaios clínicos e englobando mais de 19.700 pacientes seguidos, em sua maioria, por pelo menos três anos, após implante randomizado de stents farmacológicos ou convencionais, evidenciaram que os eluidores de sirolimus significativamente reduziam a taxa de infartos agudos do miocárdio (não-fatais de imediato, mas potencialmente incapacitantes e mortais a médio e longo prazos), em comparação ao observado tanto com os eluidores de paclitaxel como com os não-farmacológicos ${ }^{15}$. Adicionalmente, evidências mais recentes, oriundas de registros clínicos, são sugestivas inclusive de redução de mortalidade associada ao emprego de stents farmacológicos ${ }^{16}$, em comparação aos convencionais, quando aqueles são utilizados em cenários anatômicos mais complexos, distintos dos verificados nas condições mais restritas dos estudos aleatorizados iniciais.

Essas observações científicas complementares aos resultados individuais dos estudos controlados e randomizados tornam bastante plausível a hipótese corrente de que, justamente para pacientes com condições clínicas e/ou angiográficas mais difíceis daquelas contempladas nos estudos randomizados - isto é, nas situações do "mundo real" refletidas pelos registros -, os stents farmacológicos possam ser mais benéficos que seus congêneres não-eluidores de medicamentos. Embora a comprovação dessa hipótese ainda demande estudos específicos e talvez muito difíceis de se executar no cenário atual, a essência desse conceito está longe de ser negligível. Assim, é sempre oportuno lembrar que existe usualmente profunda margem entre o que se observa no âmbito restrito e relativamente artificializado dos estudos randomizados e o que ocorre no "mundo real". Em outros termos, a validade externa dos resultados dos estudos randomizados necessita de legitimação complementar para que a aplicabilidade a outros pacientes, circunstâncias e condições clínicas seja assegurada ${ }^{17}$.

Deve-se também ressaltar que, fundamentalmente, nesses diversos estudos aleatorizados, focando indicações e contextos bastante restritos - como é próprio das pesquisas realizadas com esse molde científico -, os stents farmacológicos sempre se mostraram capazes de reduzir substancialmente os índices de reestenose coronária (o propósito essencial de seu desenvolvimento tecnológico).

Em síntese, portanto, tais dispositivos assumem papel especial no sentido de se evitar a repetição de intervenções, incrementar a eficácia geral do tratamento, e proporcionar mais elevado nível de qualidade de vida aos pacientes com DAC ${ }^{14}$.

Essa conclusão é bastante pertinente para se afastar um falso dilema que às vezes se brande no contexto das intervenções médicas dirigidas ao tratamento de afecções crônicas, como a DAC: ministrar medicamentos ou procedimentos que, sem exercer efeito mensurável na sobrevida, afetem sobremaneira a qualidade de vida. O falso dilema deve ser rejeitado com veemência, pois nossos objetivos nesse contexto não devem se adstringir à simples redução da mortalidade ou a diminuir sintomas, mas, sim, a incrementar a sobrevida em condições as mais saudáveis possíveis. E nesse contexto há indícios bastante persuasivos de que o emprego de stents farmacológicos, em aplicações selecionadas, possa, de fato, contribuir de forma nítida para que nosso duplo objetivo seja alcançado.

Sumarizando, é inegável a existência de respaldo científico, além de base ética e legal, para a atuação do médico, quando da indicação de stents farmacológicos, desde que se observe a boa prática médica, como recomendado nas diretrizes societárias. A ação 
de operadoras de planos de saúde, por meio de sua auditoria médica, no acompanhamento e fiscalização da conduta do cardiologista intervencionista é legítima, mas deve ser sempre balizada nos interesses reais do paciente, nunca na busca da simples intenção de redução de custos com despesas hospitalares ou procedimentos.

\section{A PROPÓSITO DA RESPONSABILIDADE MÉDICA NA INDICAÇÃO E NO IMPLANTE INTRACORONÁRIO DOS STENTS FARMACOLÓGICOS}

Como enfatizado, os stents farmacológicos surgiram como promessa de solução para o desalentador problema do fenômeno da reestenose após angioplastia coronária. Ao entusiasmo inicial em face da divulgação dos resultados excepcionalmente bem-sucedidos no controle da reestenose coronária, verificados em grandes estudos multicêntricos aleatorizados, seguiuse certa cautela, quando se notificou a ocorrência de casos de trombose tardia desses stents ${ }^{18,19}$, entidade clínica até então pouco diagnosticada com o emprego dos stents convencionais (não-farmacológicos), pois, apesar de rara, tal complicação podia se associar a infarto do miocárdio e óbito.

Assim, mesmo no contexto de sua expressiva eficácia para a finalidade primária de seu desenvolvimento (o controle da reestenose), a questão relativa à segurança dos stents farmacológicos emergiu muito forte, despertando grande interesse, quanto a suas causas e a seu controle. O próprio Food and Drug Administration (FDA), que havia liberado o uso desses dispositivos após análise meticulosa envolvendo diversos especialistas de relevo, reavaliou o perfil de segurança desses produtos ${ }^{20}$. A principal conclusão dessa fase de reavaliação foi a ênfase na importância do uso, por um ano, de terapia antiplaquetária dupla com ácido acetilsalicílico (AAS) e tienopiridínicos ${ }^{21}$. Constatou-se, também, que nas indicações ditas on label (descritas na bula do produto), e respaldadas por estudos controlados e aleatorizados, não havia incremento do número de infartos e óbitos a médio e longo prazos, comparativamente ao grupo controle que recebera stents convencionais $^{22}$. Todavia, se considerados os casos mais complexos, que não estavam incluídos nos estudos que avaliaram os stents farmacológicos, observava-se tendência a maior frequência da taxa de eventos trombóticos tardios e muito tardios (além de um ano após o implante). Tais indicações são denominadas off label (não constantes da bula), e não integravam os critérios de inclusão dos estudos controlados e randomizados.

Embora a incidência associada aos stents farmacológicos pareça ser apenas um pouco maior que a verificada com os stents convencionais, a ocorrência de trombose tardia intrastents farmacológicos tem relevantes implicações éticas e legais no cenário off label, pois a bula do produto é clara quando afirma não estar integralmente definido o perfil de segurança e eficácia desses stents em contextos fora de algumas indicações clássicas. A título de exemplificação, para o stent Cypher $^{\mathrm{TM}}$, o primeiro a ser desenvolvido, são feitas as seguintes recomendações (em transcrição literal da bula):

\section{"8.1 Utilização em populações específicas de pacientes.}

A segurança e eficácia do stent coronário CYPHER SELECT de eluição de sirolimus ainda não foram estabelecidas para as seguintes populações de pacientes:

- Pacientes com trombos nos vasos não resolvidos no local da lesão.

- Pacientes com diâmetros de vaso de referência da artéria coronária inferiores a 2,25 mm.

- Pacientes com lesões desprotegidas localizadas na artéria coronária principal esquerda.

- Pacientes com vasos sinuosos que poderão prejudicar a colocação do stent na região da obstrução ou proximais à lesão.

- Pacientes que sofreram recentemente um enfarte agudo do miocárdio, onde existam indícios de trombos ou fluxo prejudicado.

- Pacientes com oclusões totais crônicas.

- Pacientes com tratamento por braquiterapia da lesão-alvo.

Ainda não foi estabelecida a segurança e eficácia da utilização do tratamento por braquiterapia, dos dispositivos de aterectomia mecânica (cateteres de aterectomia direcional, cateteres de aterectomia rotacional) ou dos cateteres de angioplastia a laser para tratar a estenose intra-stent de um Stent coronário CYPHER SELECT com eluição de sirolimus."

No caso do stent Taxus Liberté ${ }^{\mathrm{TM}}$, o segundo disponibilizado comercialmente, a afirmação restritiva é ainda mais taxativa, pois tais situações são definidas como contraindicações ao emprego desse stent, como se segue literalmente na bula:

"Contra-Indicações:

- Conhecida hipersensibilidade ao paclitaxel e compostos estruturalmente relacionados;

- Conhecida hipersensibilidade ao polímero ou seus componentes individuais (ver detalhes na Seção 1.2.2, Transportador - Polímero Translute, acima);

- Conhecida hipersensibilidade ao aço inoxidável;

- Reação severa a agentes de contraste que não possam ser adequadamente pré-medica- 
dos antes do procedimento de colocação do stent TAXUS Liberté;

- Pacientes nos quais terapia antiplaquetária ou anticoagulante seja contra-indicada;

- Reestenose no stent;

- Infarto do miocárdio < 72 horas antes do procedimento de colocação do stent TAXUS Liberté:

- Colocação do stent de enxertos de veia safena;

- Artéria coronária principal esquerda não protegida;

- Oclusão total do vaso alvo;

- Lesões altamente calcificadas;

- Lesões envolvendo segmentos arteriais com anatomia altamente tortuosa;

- Lesões envolvendo uma bifurcação;

- Fração de ejeção ventricular esquerda < 30\%;

- Choque cardiogênico;

- Presença de trombo intraluminal definitivo ou provável;

- Qualquer paciente considerado como tendo uma lesão que possa impedir o desdobramento apropriado do stent.

- Colocação direta do stent de oclusões totais crônicas

- Lesões contendo trombo."

De forma indubitável, diante do exposto, depreende-se que, ao indicar esses stents em tais situações, o médico assumiria, integralmente, conduta de risco ante seu paciente, pois o próprio fabricante afirma, de maneira categórica, que nesses cenários o dispositivo em questão ainda não tem seu desempenho clínico plenamente validado.

A atividade médica no Brasil, como muitas outras, é regulada em três esferas: criminal, civil e ética. A apuração das respectivas responsabilidades, quando devidas, dar-se-á nos âmbitos judicial (civil e criminal) e dos Conselhos de Medicina. É previsto um ordenamento jurídico específico para cada situação.

Como já enfatizado, dentre os princípios consagrados na deontologia médica destaca-se o da autonomia, sendo conveniente frisar, a esse título, que o médico deve utilizar todos os meios de diagnóstico e tratamento disponíveis e a seu alcance em benefício do paciente, conforme dispõe o artigo 57. Em aditamento, pelo estabelecido no artigo 29, que trata do erro médico, veda-se a prática de atos danosos ao paciente, que possam caracterizar culpa, ou seja, imperícia, negligência e imprudência.

Assim, o médico, ao assumir indicar, livremente, determinado tratamento ou, mesmo, empregar mate- riais cuja segurança e eficácia, em situações clínicas estritamente consignadas, não estejam completamente definidas, adota conduta de risco, mormente quando o próprio fabricante faz menção explícita a esse aspecto na bula do produto, excetuando-se, em princípio, os estados de necessidade absoluta ou premente, em que o ato médico possa se impor como única alternativa para salvar a vida.

Tal violação de conduta poderia ser caracterizada como imprudência ou imperícia médica, como acentua o consagrado civilista brasileiro Miguel Kfouri Neto, em sua obra "Responsabilidade Civil do Médico"12, ao discorrer sobre o tema: "No campo médico, entretanto, a dificuldade reside em se distinguir a imprudência da imperícia - e também na análise em torno do seguinte fato: o médico, ao se definir por determinada intervenção, agiu com imperícia, pois não conhecia a fundo os riscos que envolvia, ou porque, tendo perfeita consciência do risco, resolveu avançar sua ação além dos limites da licitude".

No mesmo sentido, enfatiza Basileu Garcia ${ }^{23}$, "consiste a imprudência em enfrentar, presumivelmente, um perigo". Exemplifica, taxando de imprudente notável cirurgião que, por vaidade, resolve empregar técnica cirúrgica perigosa, sem comprovada eficiência, abandonando o seguro processo habitual. Não é imperito nem negligente, pois redobra seus cuidados, mas o paciente pode morrer em decorrência de sua imprudência.

Apenas a título de ilustração, deve-se enfatizar o disposto no Código Civil Brasileiro em seus artigos 186, 927 e 949:

"Art. 186. Aquele que, por ação ou omissão voluntária, negligência ou imprudência, violar direito e causar dano a outrem, ainda que exclusivamente moral, comete ato ilícito."

“Art. 927. Aquele que, por ato ilícito (artigos. 186 e 187), causar dano a outrem, fica obrigado a repará-lo."

"Art. 949. No caso de lesão ou outra ofensa à saúde, o ofensor indenizará o ofendido das despesas do tratamento e dos lucros cessantes até ao fim da convalescença, além de algum outro prejuízo que o ofendido prove haver sofrido."

Em adição, é oportuno, igualmente, fazer menção às obrigações impostas ao médico pela legislação do consumidor, realçando-se o dever de informar, adequadamente, ao paciente, acerca dos riscos inerentes aos procedimentos por ele executados. Nessa lei, o fabricante do produto equipara-se ao médico na condição de fornecedor, existindo por vezes uma responsabilidade compartilhada, como se segue:

“Art. 3o - Fornecedor é toda pessoa física ou jurídica, pública ou privada, nacional ou estran- 
geira, bem como os entes despersonalizados, que desenvolvem atividade de produção, montagem, criação, construção, transformação, importação, exportação, distribuição ou comercialização de produtos ou prestação de serviços."

"Art. 8o - Os produtos e serviços colocados no mercado de consumo não acarretarão riscos à saúde ou segurança dos consumidores, exceto os considerados normais e previsíveis em decorrência de sua natureza e fruição, obrigando-se os fornecedores, em qualquer hipótese, a dar as informações necessárias e adequadas a seu respeito."

"Parágrafo único. Em se tratando de produto industrial, ao fabricante cabe prestar as informações a que se refere este artigo, através de impressos apropriados que devam acompanhar o produto."

"Art. 9o - O fornecedor de produtos e serviços potencialmente nocivos ou perigosos à saúde ou segurança deverá informar, de maneira ostensiva e adequada, a respeito da sua nocividade ou periculosidade, sem prejuízo da adoção de outras medidas cabíveis em cada caso concreto."

Com efeito, também se incluem como passíveis de responder por dano aos pacientes os hospitais, as operadoras de planos de saúde e até mesmo os cardiologistas que encaminham seus clientes para realização de procedimentos intervencionistas. No caso de hospitais e operadoras de planos de saúde, rege a teoria do risco ou imprevisão, segundo a qual estes responderão independentemente da existência de culpa, bastando para isso apenas que se prove a ocorrência de nexo causal entre o fato e o dano ao paciente. Trata-se de uma forma excepcional de responsabilização no âmbito do Direito Obrigacional, a responsabilidade objetiva, a qual se diferencia da regra, que consiste na responsabilidade subjetiva, para a qual é imprescindível o exame do elemento anímico, da culpa do agente, associado à ocorrência do nexo causal.

Destarte, é inteligível que essas empresas se acautelem, estabelecendo regulamentos restritivos aos médicos, sejam eles seus funcionários, credenciados ou cooperados, recomendando que apenas utilizem materiais e medicamentos, quando estritamente de acordo com as orientações de seus fabricantes. Quanto aos cardiologistas que encaminham seus pacientes para realização de procedimentos intervencionistas, poderá se caracterizar a culpa in eligendo, isto é, culpabilidade que advém da má escolha daquele a quem se confia a prática de um ato ou o adimplemento da obrigação.

Diante do complexo contexto da assistência à saúde no Brasil e suas implicações éticas e legais, o emprego de stents farmacológicos em situações clínicas ditas "não constantes do bulário" poderia configu- rar, à primeira vista, conduta de risco, isto é, imputável de culpa, para os que o executam. Todavia, com base em resultados recentes de pesquisas clínicas já publicadas, demonstrando a segurança e eficácia dessa técnica em contexto diverso do explicitamente recomendado pelo fabricante, requer-se, prementemente, atualização das indicações. Em outros termos, seria conveniente que algumas dessas novas indicações fossem referendadas pelo fabricante, na bula, como plausíveis e defensáveis cientificamente. Assim, seria ampliado criteriosamente o uso desses dispositivos, e indiscutivelmente se aumentaria a segurança jurídica para atuação do médico. Como exemplificação, seria razoável validar o tratamento, com stents farmacológicos, da reestenose intrastent convencional ${ }^{24}$, de lesões em bifurcações $^{25}$ ou em vasos de menor calibre ${ }^{26}$. Essa validação deveria ser acompanhada de ressalva relativa a que, nessas situações, os resultados clínicos poderiam ser distintos dos observados nas indicações habituais, ou seja, as constantes do bulário.

A chancela das novas indicações por sociedades científicas, mediante diretrizes criteriosas e bem fundamentadas $^{13}$, também contribuiria para atenuar ou mesmo anular a culpa presumível, objeto do suposto ato ilícito. No entanto, caso o médico, mesmo conhecendo essas implicações, queira realizar implante de stents farmacológicos em situações "não constantes do bulário", deve acautelar-se e elaborar termo de consentimento esclarecido ${ }^{27}$, a ser implementado previamente ao procedimento. Em tal documento devem constar todos os aspectos vinculados a essa intervenção, quais sejam: seus riscos, possíveis complicações, alternativas terapêuticas e possibilidades de resultados a curto e longo prazos. A obtenção desse termo constituirá elemento formal de autorização esclarecida pelo paciente, com testemunho de seus familiares, quanto ao procedimento.

Em contrapartida, evidenciando a complexidade das situações em tela, destaque-se que as precauções expressas em virtude do emprego de stents farmacológicos, em situações fora do bulário, aplicam-se igualmente ao uso de stents convencionais em contexto clínico no qual esteja comprovada a supremacia de resultados obtidos com os stents farmacológicos. Nesse particular, compete destacar a necessidade de esclarecimento detalhado ao paciente acerca dos contrastes e confrontos relativos à terapêutica com ambos os stents, mormente no que se refere à provável necessidade de repetição de procedimentos de revascularização - bem mais elevada com os stents convencionais. Note-se que a escolha do stent a ser empregado deve ser decorrente de decisão esclarecida do paciente, em consonância com seu cardiologista clínico. Ressalte-se ainda que mesmo os pacientes que se servem do sistema público de saúde, aos quais a priori não são ofertados stents farmacológicos, devem ser adequadamente cientificados no tocante às expectati- 
vas comparativas de resultados do tratamento entre os dois tipos de stent. Dessa forma, o emprego de stents convencionais em situações em que esteja comprovada a inferioridade de seus resultados ante os divisados com os stents farmacológicos - indicações on label dos stents farmacológicos - sem a aquiescência esclarecida do paciente adquire caráter semelhante ao comentado para o uso de stents farmacológicos em situações off label.

Essa normatização, aqui sugerida, contribuirá para elevação harmoniosa do relacionamento médico-paciente, diante de contexto complexo, em que os benefícios potenciais de dispositivos que inegavelmente configuram avanço tecnológico e científico devem ser criteriosamente sopesados com relação à incerteza sobre seu perfil de comportamento a longo prazo.

\section{O EMPREGO DOS STENTS FARMACOLÓGICOS E AS RECLAMAÇÕES NO PODER JUDICIÁRIO}

O Poder Judiciário tem sido o desaguadouro natural das irresignações dos usuários com as operadoras de planos de saúde, notadamente por infrações ao Código de Defesa do Consumidor, Lei no 8.078/90, à legislação dos planos de saúde, Lei 9.656/98, e à garantia constitucional do direito à saúde, consubstanciada nos artigos 6e e 196 da Constituição Federal. Na maioria dos casos envolvendo planos de saúde, impetram-se ações de "antecipação de tutela", pleiteando a concessão de medidas liminares que determinem a autorização desses procedimentos. Já quando a controvérsia envolve o poder público, representado pelo Estado ou por pessoa jurídica integrante da Administração Pública, direta ou indireta, é mais comum que se utilize o "mandado de segurança". Esses litígios antecedem a era dos stents farmacológicos, pois desde 1994, quando da introdução dos stents convencionais, já se configuravam situações similares.

Uma das razões aludidas para a negativa de autorização de implante de stents se deve à alegação de que, como tais dispositivos são próteses, não há cobertura contratual para eles. Torna-se oportuno aduzir que esse aspecto foi parcialmente suprido com o advento da Lei 9.656/98, que obriga a autorização de uso de próteses ou órteses e seus acessórios desde que vinculados ao ato cirúrgico. Entretanto, persistem no mercado alguns planos de saúde, ditos não regulamentados, contratados antes da vigência da legislação retrocitada, em que tais restrições ainda se observam.

Mas é conveniente aprofundarmos essa questão, em sua essência. A alegação esposada pelas operadoras de planos de saúde ao qualificar o stent como prótese não é de todo infundada, pois a própria Associação Médica Brasileira, desde 1990, quando fez figurar pela primeira vez em sua antiga tabela de honorários o procedimento para implante de stent, de- nominou-o implante de endoprótese intracoronária. Em decorrência dessa denominação, criaram-se as condições para restrição ao emprego desses dispositivos com base naquelas objeções. Entretanto, a Classificação Brasileira Hierarquizada de Procedimentos Médicos (CBHPM) - referência atual dos atos médicos realizados no Brasil, editada por meio de resolução normativa do CFM 1.673/2003 - suprimiu a expressão prótese para identificar o procedimento de implante de stent. Ainda assim, hoje se discute, em vários fóruns médicos, a real natureza conceitual do stent: tratar-se-ia de uma prótese ou órtese?

Encontramos interessante referência relativa ao significado dos vocábulos prótese e órtese no texto do professor Joffre M. de Rezende ${ }^{28}$, segundo o qual, apesar da semelhança, essas palavras, derivadas do grego, têm etimologia diversa. Também pode ser empregado o termo "próstese", como sinônimo de "prótese". "Prótese" e "próstese" são formadas com o mesmo tema, thésis, do verbo títhemi, significando colocar, acrescentar. Em grego clássico, também já havia, pré-formados, os termos próthesis e prósthesis, o primeiro na acepção de "colocação à frente", "diante de", e o segundo no sentido de acréscimo, adição. Hipócrates empregou o termo "próstese" em referência à colocação de talas de madeira na imobilização de fraturas do antebraço. Já "órtese" é oriundo da palavra grega orthósis, formada, por sua vez, de orthós, reto, direito, e o sufixo -sis. Esse sufixo grego expressa ação, estado ou qualidade. Orthósis, no caso, é a ação de endireitar, de tornar reto, retificar.

No dicionário Houaiss (Editora Objetiva, 2001) designa-se como "prótese" o "dispositivo implantado no corpo para suprir a falta de um órgão ausente ou para restaurar uma função comprometida"; também "qualquer aparelho que vise suprir, corrigir ou aumentar uma função natural, a exemplo da audição ou da visão". O significado da palavra órtese não é encontrado nos dicionários tradicionais da língua portuguesa, como os elaborados pelas equipes de Caldas Aulete (Editora Delta, 4a ed., 1958), Houaiss e Aurélio Buarque de Holanda (Editora Nova Fronteira, 3a versão eletrônica, 2000). Todavia, tal fato é explicável, pois foge do objetivo desses compêndios a inclusão de todos os verbetes do vocabulário técnico. Diferentemente da prótese, que substitui, no todo ou em parte, um órgão que foi perdido, a órtese é uma ajuda externa, destinada a suplementar ou a corrigir uma função deficiente ou mesmo complementar o rendimento fisiológico de um órgão ou membro, que tenham sua função diminuída (exemplos tradicionais são as antigas fundas para hérnia, o colar cervical e as talas de material plástico para o punho ou para o braço). Essa conceituação, eminentemente técnica, parece aplicar-se bem ao que realizamos quando implantamos stents coronários, para evitar que a artéria continue a manter-se estenosada. 

para Incorporação dessa Tecnologia nos Sistemas de Saúde Público e Privado no País. Rev Bras Cardiol Invas. 2009 ;17(1):117-32.

Para melhor compreensão do significado do termo stent e sua definição como órtese ou prótese, é conveniente nos reportarmos aos primórdios de seu emprego. Há diversas versões para essas origens primordiais, que foram adequadamente discutidas por Trindade $^{29}$. Em uma das mais difundidas, que apoiaria a noção de se tratar o termo de um epônimo, consta que em meados do século XIX o dentista britânico Charles Thomas Stent (1807-1855) desenvolveu um material de impressão dental contendo guta-percha, estearina e talco, produzido e comercializado com a ajuda de seus filhos Charles Robert (1845-1901) e Arthur Howard (1859-1900), os quais também se tornaram dentistas. Em 1899, esse composto foi patenteado sob o nome de stent. Durante a 1a Guerra Mundial, o cirurgião plástico Johannes Fredericus Samuel Esser descobriu que esse stent poderia também ser usado para fazer moldes fixadores de enxertos de pele no local. Em publicação de 1917, referiu-se a tais moldes como "stents moldes". Nas décadas seguintes, o termo stent tornou-se corriqueiro na área de cirurgia oral e plástica. O significado de stent continuou a ser expandido para incluir outros tipos de suportes artificiais para tecido humano. Em 1954, o cirurgião americano William Remine aplicou o termo stent a tubo de polietileno provendo suporte a uma anastomose em reconstrução biliar experimental. Em 1966, stent passou a ser empregado para designar suportes tubulares na cirurgia cardiovascular. Em 1972, o termo também se aplicou para designar alguns suportes urológicos. A partir de 1987, igualmente, passou a ser empregado em cardiologia intervencionista.

Com efeito, note-se que nem o dispositivo idealizado por Charles Stent, o qual a posteriori recebeu seu nome, tampouco os stents moldes de Esser podem ser conceitualmente designados como próteses. Assim, desde o princípio de sua aplicação o termo stent não foi utilizado para expressar prótese, mas sim órtese, uma vez que constitui uma ajuda externa destinada a suplementar ou auxiliar um determinado procedimento ou função, em sintonia com a própria etimologia grega da palavra orthós. Na cardiologia intervencionista, o stent pode ser descrito como uma malha metálica expansível confeccionada a partir da matéria-prima de aço inoxidável ou outras ligas, cortada a laser com precisão submilimétrica. Nesse contexto, tem função eminentemente de completar e aperfeiçoar a técnica da angioplastia coronária realizada por via transluminal, com acesso percutâneo, originalmente realizada com expansão de balões.

O Poder Judiciário brasileiro, em diversas manifestações, tem considerado o stent como órtese, a exemplo da decisão proferida pela insigne desembargadora Maria Henriqueta Lobo, do Tribunal de Justiça do Estado do Rio de Janeiro, na apelação cível no 2007.001.38297, em 29 de agosto de 2007, em que afirma de forma categórica: "O artefato médico stent não tem natureza de prótese, uma vez que não substitui qualquer órgão ou sua parte, no corpo do autor. Trata-se de instrumento necessário para garantir a abertura das artérias e que complementa o tratamento de uma lesão que acometeu parte do coração (uma artéria) tratada por angioplastia, visando melhorar o prognóstico evolutivo do paciente". Em aditamento, ressalte-se que tal conceito, no âmbito da Justiça do Estado do Rio de Janeiro, está definitivamente incorporado, trata-se de matéria pacificada, pois integra a Súmula 112 de seu egrégio Tribunal de Justiça, na qual se define stent como órtese: "É nula, por abusiva, a cláusula que exclui de cobertura a órtese que integre, necessariamente, cirurgia ou procedimento coberto por plano ou seguro de saúde, tais como 'stent' e marcapasso".

Em sintonia com o Judiciário do Estado do Rio de Janeiro, o Tribunal de Justiça do Rio Grande do Sul também entende que o stent não pode ser qualificado como prótese, considerando-o como um material especial inerente ao procedimento cirúrgico. Tal entendimento fica bem definido no julgado que se segue: "Todavia, já está pacificado o entendimento jurisprudencial no sentido que os Stents não se referem a órtese ou prótese, sendo material cirúrgico, não alcançado, portanto, pela cláusula contratual que prevê a exclusão de próteses e órteses dos riscos cobertos no plano de saúde" (cláusula VII, 7.1, item "n", fl. 13). O desembargador Artur Arnildo Ludwig, na Apelação Cível no 70011448347, julgada em 26 de outubro de 2005, ao enfrentar a matéria esclareceu que '(...) esta 6a Câmara Cível, em reiterados julgados, tem firmado posicionamento no sentido de que o stent não é considerado efetivamente uma prótese, na acepção médica da palavra, já que não substitui, total ou parcialmente, a artéria coronariana, mas serve apenas de reforço de estrutura do órgão, devido à moléstia apresentada pelo paciente $(. . .)^{\prime}$. Com isso, considerando os reiterados entendimentos jurisprudenciais oriundos do Tribunal de Justiça do Estado, resta evidente que o stent não se configura como prótese ou órtese, estando coberto pelo plano de saúde contratado".

Como exposto, o instrumento jurídico geralmente utilizado para assegurar direitos no caso da negativa de operadoras de plano de saúde em autorizar o procedimento para implante de stent é a "ação de tutela antecipada". Os juízes, na concessão de medidas liminares, observam a existência do fumus boni juris e/ou periculum in mora. Na primeira condição, verifica-se a fumaça do bom direito representado pelo entendimento que um julgador tem diante de uma alegação que lhe foi submetida. Na segunda, observam-se os riscos da decisão tardia, perigo em razão da demora. Deve ser demonstrado, por meio de prova inequívoca, que o direito pleiteado deve ser aceito pelo juiz de maneira urgente, pois não pode aguardar a sentença final, isto é, o trâmite normal do processo. 
Assim, em casos extremos, nos termos do artigo citado, o juiz concederá a "tutela antecipada" para evitar que um dano maior seja causado em virtude da demora do Judiciário.

O papel do médico, nesse contexto, assume considerável relevo, pois é com esteio nas suas informações, por meio de relatórios médicos circunstanciados, que se produzirá prova para fundamentar a ação judicial. Ao médico não compete fazer juízo de valor acerca da plausibilidade do direito do paciente, mas sim relatar de forma clara e concisa as razões que norteiam a sua requisição de autorização para implante de stent, preferencialmente recorrendo à Medicina Embasada em Evidências e às diretrizes societárias. Destaque-se que o exagero no diagnóstico ou prognóstico, além de constituir ilícito ético, pode induzir o magistrado a erro de avaliação, com possíveis consequências no decorrer da demanda. A concessão da medida liminar não assegura, por completo, o êxito da ação, uma vez que seus efeitos podem ser suspensos em razão de agravos instrumentais interpostos pelas operadoras de planos de saúde ante os tribunais dos Estados ou "recursos especiais" no Superior Tribunal de Justiça (STJ).

À guisa de ilustração, recorremos, mais uma vez, ao ementário do Tribunal de Justiça do Rio de Janeiro, nos autos do agravo de instrumento no 2007.002.24220, cujo relator foi o eminente desembargador Marco Aurélio Fróes, no qual foi desprovido o recurso interposto pela operadora de plano de saúde visando tornar sem efeito a concessão de "tutela antecipada" a paciente que pleiteava o custeio de stents farmacológicos. $\mathrm{Na}$ sua decisão, o douto magistrado assim se pronunciou: "Agravo de instrumento interposto contra decisão que deferiu antecipação da tutela para que a agravante custeasse a internação da autora para realização do implante de stent farmacológico indicado pelo laudo médico, sob pena de multa diária de R\$ 200,00. Quanto à antecipação da tutela, trata-se de questão pacificada neste Tribunal, que mereceu, inclusive, especial atenção ante a reincidência de recursos em torno da questão, pelo que se originou o Enunciado no 8 do CEDES, atual Súmula 59 do TJERJ. O receio de dano irreparável ou de difícil reparação está visível, diante das condições de saúde e financeiras da agravada, pois, sem condições de custear seu tratamento, os danos seriam, no mínimo, de difícil reparação, o que já é uma circunstância fática a demonstrar que a ocorrência do dano gera a necessidade de antecipação da tutela".

No mesmo sentido, igualmente decidiu o Tribunal de Justiça do Paraná, no agravo de instrumento no 406.458-8, da Comarca de Mandaguari, cujo relator foi o douto desembargador Guimarães da Costa, negando provimento ao recurso interposto pela Caixa de Assistência dos Funcionários do Banco do Brasil (CASSI), que pleiteava tornar sem efeito a "antecipação de tutela" concedida pelo magistrado de primeiro grau, determinando que a referida operadora de plano de saúde custeasse os stents farmacológicos implantados em seu usuário.

Por outro lado, mas em igual sentido, o mesmo pretório decidiu prover o agravo de instrumento no 0346552-1, interposto por usuário da Unimed de Maringá, para modificar a decisão do magistrado de primeiro grau, na qual foi negada a "antecipação de tutela" em favor da Cooperativa, determinando o custeio da angioplastia com implante de stents farmacológicos por esse instituição. A operadora de plano de saúde, a despeito da solicitação do médico assistente, autorizara apenas o implante de stent convencional. Na decisão, o desembargador Nilson Mizuta, relator, realça o papel do médico na escolha do procedimento mais adequado ao paciente, como se segue: "(...) o médico do agravante indicou e justificou, de forma clara, a necessidade de implantação de stent diferenciado, ou seja, devido à taxa elevada de reestenose' (fl. 54), sendo certo, ainda, ser portador de doença coronariana severa' e já ter se submetido a três angioplastias nos últimos anos (fl. 55). É importante salientar que, ao menos nesse momento, prevalece a recomendação do médico responsável pelo seu tratamento, em detrimento de manifestação do auditor da ré, por razões óbvias (...)". Entendimento semelhante é o do desembargador Renato Nalini, do Tribunal de Justiça de São Paulo (TJ-SP), para o qual o médico, "estudioso de seu ofício, não quedaria em eventuais temeridades. A medicina não é ciência exata e a estratégia de tratamento de cada paciente está confiada a seu médico. Presume-se que facultativo formado em Universidade cuja criação foi permitida pelo Poder Público, cuja fiscalização a ele compete e cujo credenciamento dos egressos incumbe a órgão legitimado de representação, saiba discernir o que se mostra adequado para o seu paciente".

Apesar de a maioria das decisões prolatadas nas instâncias superiores do Judiciário dos diversos Estados do Brasil favorecerem os usuários, que têm seus direitos restringidos em virtude de exclusões consideradas abusivas ou ilegais constantes nos contratos, há situações nas quais foram consideradas as alegações das operadoras de plano de saúde, a exemplo do que foi decidido no Tribunal de Justiça do Rio Grande do Sul, no agravo de instrumento no 70019767078, o qual manteve a decisão do juízo de primeira instância, negando provimento ao pretendido pelo usuário do Instituto de Previdência do Estado do Rio Grande do Sul (IPERGS), o qual buscava autorização para ser tratado com implante de stents farmacológicos. Na decisão, alegam-se questões relativas ao elevado custo dos stents farmacológicos como marcado: "Tratando-se de pedido de custeio de cirurgia para colocação de stent recoberto de droga, embora não reste dúvida quanto à necessidade da realização do ato cirúrgico, 
uma vez documentalmente comprovada a enfermidade do agravante, não merece concessão a tutela pretendida, diante do elevadíssimo custo do material empregado, sob pena de inviabilizar a prestação do serviço de saúde aos demais usuários do Instituto, em especial aquelas hipóteses que apresentam maior urgência. Além disso, embora reconhecida a gravidade da doença do agravante, salienta-se que não resta demonstrada a ineficácia da angioplastia com stent simples, ausente, assim, o risco de dano irreparável pela não-concessão da tutela pretendida".

O tema também tem sido alvo de apreciação do Superior Tribunal de Justiça, que funciona como última instância do Judiciário Brasileiro para questões não constitucionais, tendo recebido dos senhores ministros, via de regra, entendimento semelhante ao esposado nos tribunais estaduais. Em Recursos Especiais interpostos, as operadoras de planos de saúde têm sido condenadas ao pagamento de indenizações por danos materiais e morais em virtude da negativa de autorização de stents farmacológicos ou não. $O$ entendimento jurisprudencial sobre o tema pode ser sintetizado na íntegra das ementas da colenda corte superior, como em destaque:

\section{“REsp 993876/DF RECURSO ESPECIAL 2007/ 0234308-6}

Relatora Ministra Nancy Andrighi

Civil e processo civil. Recurso especial. Ação de indenização por danos materiais e compensação por danos morais. Recusa do plano de saúde em arcar com custos de cirurgia e implante de Stent Cypher, ao argumento de que tal aparelho seria, ainda, experimental. Alegação negada pelas provas dos autos e pela própria conduta posterior da seguradora, que nenhuma objeção impôs a idêntico pedido, em data posterior. Danos morais configurados, de acordo com pacífica jurisprudência do STJ. Perdas e danos. Possibilidade de pedido específico já na inicial, não realizado pelo autor. Impossibilidade de delegação da questão à liquidação da sentença em tal circunstância. A esteira de diversos precedentes do STJ, verifica-se que a recusa indevida à cobertura médica pleiteada pelo segurado é causa de danos morais, já que agrava a situação de aflição psicológica e de angústia no espírito daquele.

Na presente hipótese, acrescente-se ainda que a conduta do plano de saúde assumiu contornos bastante abusivos que vão muito além do mero descumprimento contratual, na medida em que houve uma negativa inicial e, a seguir, uma autorização para um segundo procedimento idêntico alguns meses depois, sem que qualquer alteração nas bases fáticas ou contratuais tivesse se operado. Evidente, portanto - conforme reconheceu o acórdão - que a primeira negativa da seguradora se resumiu a um verdadeiro ato de discricionariedade, praticado em desfavor do segurado e completamente desconectado do mínimo de razoabilidade.

O acórdão entendeu que o autor, por conveniência, deixou de precisar o valor material de um de seus pedidos relativos a perdas e danos, quando tal providência era perfeitamente possível. Nessa perspectiva, é irrelevante que, em alguns casos específicos, seja possível relegar a fixação do 'quantum' à liquidação de sentença, porque tal só se dá em face de dificuldades inerentes ao próprio julgamento e não como decorrência de mera escolha do autor em assim descrever o pedido.

Não se conhece de recurso especial na parte em que este se encontra deficientemente fundamentado. Recurso especial parcialmente provido.

REsp 986947/RN RECURSO ESPECIAL 2007/ 0216173-9

Relatora Ministra Nancy Andrighi

DIREITO CIVIL E CONSUMIDOR. PLANO DE SAÚDE. INCIDÊNCIA DO CDC. PRÓTESE NECESSÁRIA À CIRURGIA DE ANGIOPLASTIA. ILEGALIDADE DA EXCLUSÃO DE STENTS DA COBERTURA SECURITÁRIA. DANO MORAL CONFIGURADO. MAJORAÇÃO DOS DANOS MORAIS.

Conquanto geralmente nos contratos o mero inadimplemento não seja causa para ocorrência de danos morais, a jurisprudência desta Corte vem reconhecendo o direito ao ressarcimento dos danos morais advindos da injusta recusa de cobertura de seguro saúde, pois tal fato agrava a situação de aflição psicológica e de angústia no espírito do segurado, uma vez que, ao pedir a autorização da seguradora, já se encontra em condição de dor, de abalo psicológico e com a saúde debilitada.

A quantia de R\$5.000,00, considerando os contornos específicos do litígio, em que se discute a ilegalidade da recusa de cobrir o valor de stents utilizados em angioplastia, não compensam de forma adequada os danos morais. Condenação majorada. Recurso especial não conhecido e recurso especial adesivo conhecido e provido.

REsp 896247/RJ RECURSO ESPECIAL 2006/ 0079508-0

Relator Ministro Humberto Gomes de Barros

PLANO DE SAÚDE - ANGIOPLASTIA CORONARIANA - COLOCAÇÃO DE STENT - POSSIBILIDADE.

É abusiva a cláusula contratual que exclui de cobertura a colocação de stent, quando este é 
necessário ao bom êxito do procedimento cirúrgico coberto pelo plano de saúde.

\section{REsp 786283/RJ RECURSO ESPECIAL 2005/ 0165406-4}

Relator Ministro Ari Pagendler

\section{CIVIL. PLANO DE SAÚDE. DESPESAS COM STENT.}

A previsão contratual para a realização do cateterismo contém em si mesma a autorização para o uso dos meios necessários para a efetividade do procedimento. Recurso especial conhecido e provido."

Destarte, note-se que o STJ, mesmo diante de planos de saúde pactuados antes da vigência da lei 9.656/98, na qual não é prevista a cobertura de órteses e próteses, tem entendido que é abusiva a negativa de contemplar esses dispositivos como imprescindíveis a ato médico provido no contrato. Nesse sentido, realcem-se as palavras do ministro Humberto Gomes de Barros: "Vale salientar, que não importa examinar a qualificação do stent, isto é, se é prótese ou não. $\mathrm{O}$ interessante nessa questão é que a implantação do stent é condição de eficácia para um procedimento coberto pelo plano de saúde". Na mesma linha de entendimento, manifestou-se o ministro Ari Pagendler: "Nessa linha, é irrelevante saber se stent é prótese ou não, porque a previsão contratual para realização contém em si mesma a autorização para o uso dos meios necessários para efetividade do procedimento".

A par dos argumentos apresentados, há plausibilidade inquestionável de cobertura de stents, farmacológicos ou não, não importando sua qualificação como órtese ou prótese, e independente da previsão de cobertura contratual. Acrescente-se, ainda, que mesmo diante da impossibilidade de retroatividade dos efeitos da Lei 9.656/98 para alcançar os planos pactuados antes de sua vigência, a detida interpretação da legislação do consumidor tem feito o Judiciário Brasileiro considerar abusivas as cláusulas que restringem o emprego de stents.

De forma análoga, mas em outra direção, poderse-ia discutir a obrigação legal do Estado em prover stents farmacológicos no âmbito do sistema público de saúde. A Constituição Federal de 1988 consagrou a saúde como direito social: saúde é direito de todos e dever do Estado, conquista inalienável da sociedade brasileira. À luz desse princípio não há como desconsiderar a plausibilidade da oferta de stents farmacológicos por meio do Sistema Único de Saúde (SUS). Essa discussão remonta a 1999, quando os stents convencionais foram inseridos para reembolso na tabela do SUS. À época, existia cenário semelhante ao verificado hoje, em relação aos stents farmacológicos; todavia aspectos relacionados à segurança da angioplastia apenas com balão conferiam maior ênfase à necessidade de incorporar a tecnologia (o stent).
Assim, embora seja relevante, do ponto de vista da economia em saúde, discutir-se a custo-efetividade dos procedimentos médicos ofertados como política de governo, convém tratar, neste momento, o conflito entre princípios que contrapõem direitos individuais e coletivos.

Enquanto nas situações que envolvem planos de saúde a discussão é essencialmente centrada no âmbito do Direito do Consumidor e do Direito Privado, quando tais casos envolvem o poder público, o debate torna-se muito mais calcado no Direito Constitucional. Em si, o fato implica maior complexidade inerente, uma vez que se torna necessário adentrar a seara da dogmática dos direitos fundamentais, notadamente na intrincada questão da efetivação dos direitos sociais, dentre os quais se pode destacar o direito à saúde, como expresso no artigo $6^{\circ}$ da Constituição Federal:

"Artigo 6ำ - São direitos sociais a educação, a saúde, o trabalho, o lazer, a segurança, a previdência social, a proteção à maternidade e à infância, a assistência aos desamparados, na forma desta Constituição".

Nossa Carta Magna ainda assegura o direito à saúde em seu artigo 196:

"A saúde é direito de todos e dever do Estado, garantido mediante políticas sociais e econômicas que visem à redução do risco de doença e de outros agravos e ao acesso universal e igualitário às ações e serviços para sua promoção, proteção e recuperação."

A doutrina constitucionalista tradicional costumava considerar as normas garantidoras de direitos sociais como normas programáticas, as quais não seriam eficazes plenamente desde sua promulgação, mas somente a partir do momento em que o Estado, por meio do Poder Executivo, desenvolvesse políticas públicas para implementá-las. Desse modo, constitúa-se dever do Estado garantir educação ou saúde aos cidadãos. Sob o prisma daquela visão mais antiquada, não havia, contudo, o estabelecimento imediato de um direito subjetivo do indivíduo, sem o qual ele era privado da pretensão de pleitear a efetivação do direito social perante o Poder Judiciário.

A jurisprudência mais recente, no entanto, tem seguido a concepção da moderna doutrina constitucionalista alemã, a qual concebe que as normas garantidoras de direitos sociais são de vigência imediata unmittelbar geltendes Recht (direito imediatamente vigente). Tais normas não só conferem um dever estatal, mas também um direito subjetivo a seus titulares, podendo eles exigir que o Estado cumpra o dever que The é estabelecido na Constituição. A participação do Judiciário na implementação dos direitos fundamentais (ativismo judicial), porém, é alvo de críticas. Ao 

para Incorporação dessa Tecnologia nos Sistemas de Saúde Público e Privado no País. Rev Bras Cardiol Invas. 2009 ;17(1):117-32.

conceder um stent farmacológico a um paciente do SUS, no intuito de efetivar seu direito à saúde, o Judiciário estaria implementando políticas públicas e, por conseguinte, assumindo uma função típica do Poder Executivo, segundo a clássica teoria da tripartição funcional do poder do barão de Montesquieu. Ressaltase, todavia, que a teoria de Montesquieu, desenvolvida durante o lluminismo, não deveria mais ser vista de maneira estanque, uma vez que a atual ordem constitucional consagra o modelo de Estado Social, em cujo cerne está a concretização dos direitos sociais na maior medida possível.

Se, por um lado, é inegável que o direito à saúde é consagrado constitucionalmente, também é patente que os recursos econômicos para efetivá-los são sempre finitos. Tal questão ficou evidente desde que se começou a exigir a implementação de direitos sociais perante os tribunais. Na Alemanha, é emblemática a numerus-clausus Entscheidung [decisão dos numerus clausus - BverfGE n. 33, 303 (333)], na qual se consagrou que as pretensões exigíveis do Estado estão restritas àquilo que é possível e razoável, do ponto de vista econômico. Por meio de tal decisão, a Corte Constitucional Alemã (Bundesverfassungsgericht) aplicou, pela primeira vez, a chamada cláusula da reserva do possível (Vorbehalt des Möglichen), como proposta pelo célebre jurista Peter Häberle ${ }^{30}$.

O conceito de reserva do possível está presente em algumas decisões judiciais brasileiras envolvendo stents farmacológicos, notadamente quando não se pretende arcar com as despesas do tratamento. É esse o caso do seguinte agravo de instrumento, interposto contra o Instituto de Previdência do Estado do Rio Grande do Sul, perante o Tribunal de Justiça desse Estado. Entende o desembargador João Armando Bezerra Campos, relator do caso, que: "A pretensão do agravante, ainda, encontra limite no princípio da reserva do possível, devendo a sua consecução respeitar as condições do ente público de realizá-la dentro de suas possibilidades orçamentárias, cotejados os iguais direitos de mesma natureza. Tratando-se de pedido de custeio de cirurgia para colocação de stent coberto de droga, embora não reste dúvida quanto à necessidade da realização do ato cirúrgico, uma vez documentalmente comprovada a enfermidade do agravante, não merece concessão a tutela pretendida, diante do elevado custo do material, sob pena de inviabilizar a prestação do serviço de saúde aos demais usuários do Instituto, em especial aquelas hipóteses que apresentam maior urgência. Além disso, embora reconhecida a gravidade da doença do agravante, salienta-se que não resta demonstrada a ineficácia da angioplastia com o stent simples, ausente, assim, o risco de dano irreparável pela não-concessão da tutela pretendida".

Mister se faz destacar que, apesar de eventuais indagações acerca dos gastos que um tratamento com stents farmacológicos poderia suscitar, bem como do fato de se tratar de gastos públicos sem prévia dotação orçamentária, determinado pelo Poder Judiciário - o qual prima facie não seria a instância mais adequada para a implementação de políticas públicas -, a tônica predominante na jurisprudência brasileira é favorável à concessão dos stents farmacológicos. Independentemente de serem eles considerados próteses ou órteses, de seu custo ser elevado ou não, quando pleiteado perante tribunais, o Estado vem sendo conclamado a implementar o direito à saúde, para que o artigo 196 da Carta Magna não se esvaia de significado. É esse o entendimento do ministro Celso de Mello, do Supremo Tribunal Federal, para quem tal dispositivo legal "não pode se converter em promessa constitucional inconsequente, sob pena de o Poder Público, fraudando justas expectativas nele depositadas pela coletividade, substituir, de maneira ilegítima, o cumprimento de seu impostergável dever, por um gesto irresponsável de infidelidade governamental ao que determina a própria Lei Fundamental do Estado".

Em conformidade com o que afirma o ministro, decidiu o Tribunal de Justiça do Estado de São Paulo, na Apelação Cível no 770.568-5/0-00, que cabia ao Instituto de Assistência Médica ao Servidor Público Estadual (IAMSPE) o reembolso das despesas decorrentes de tratamento com stent farmacológico. Trata-se de um caso muito semelhante ao do Instituto de Previdência do Estado do Rio Grande do Sul, mas que teve o desfecho oposto. Outro caso em que o TJ-SP decidiu pelo custeio do tratamento é o do agravo de instrumento 823.627.5/0-00, interposto contra despacho que, em "mandado de segurança" impetrado contra o Secretário Municipal de Higiene e Saúde de São José do Rio Preto, deferiu a liminar para o fornecimento de dois stents farmacológicos. Em tal decisão, o desembargador Renato Nalini manteve o entendimento do juiz de primeiro grau em relação ao custeio de tais stents, conforme a requisição médica específica.

\section{VISÃO DE SÍNTESE E CONSIDERAÇÕES FINAIS}

Os conflitos éticos e judiciais relativos ao emprego dos stents farmacológicos no Brasil decorrem em grande parte do valor agregado desses dispositivos. Por seu turno, a agregação excessiva de valor resulta do fato primordial de que aspectos relacionados à economia em saúde, em geral, e à custo-efetividade de determinados procedimentos, em particular, assumam extraordinário relevo na sociedade hodierna. Por essas razões, apesar da comprovada segurança e eficácia desses stents, em diversos cenários clínicos avaliados tanto no contexto da prática médica como no âmbito da pesquisa clínica, por quase uma década de utilização, ainda persistem contestações acerca de suas indicações, por parte dos agentes financiadores da saúde, notadamente as operadoras de planos de saúde. 

para Incorporação dessa Tecnologia nos Sistemas de Saúde Público e Privado no País. Rev Bras Cardiol Invas. 2009;17(1):117-32.

Desde 1998, com o advento da legislação específica dos planos de saúde, o setor passou a ser regulado pela ANS, a qual tem a missão de pugnar pela viabilidade e qualidade do provimento da saúde que é dispensado ao universo dos usuários desse segmento no Brasil. Para tanto, pode adotar medidas coercitivas junto às operadoras de planos de saúde, a fim de assegurar os direitos dos usuários. Todavia, em outra ponta, compromete-se, igualmente, com a saúde financeira dessas operadoras. Entre as prerrogativas da ANS inclui-se a possibilidade de intervenção, por meio de regime de direção fiscal e até de cancelamento definitivo do registro da operadora, inviabilizando sua permanência no mercado.

O cenário da cardiologia, ao longo das últimas décadas, tem registrado o constante e ingente esforço para prodigalizar à população mundial e, particularmente, à de países emergentes - que é vítima de verdadeira epidemia global de afecções cardiovasculares crônicas ${ }^{31,32}$ - novos métodos diagnósticos e intervenções terapêuticas mais seguras e eficazes. Nesse contexto, é oportuno remarcar o entendimento de Anis Rassi Jr. ${ }^{33}$, expresso em recente editorial: "A introdução da intervenção coronariana percutânea (do balão aos stents farmacológicos) é, por muitos, considerada um dos maiores avanços da cardiologia em todos os tempos. Em contrapartida, existe uma preocupação crescente no que diz respeito à escalada dos custos de saúde. Uma determinada estratégia, para ser considerada ideal, deve apresentar maior eficácia com menor custo. Entretanto, esse binômio é raro em medicina. A introdução de novos métodos diagnósticos e terapêuticos geralmente implica custos adicionais significativos".

As ponderações relativas à escalada crescente de custos são pertinentes e justificáveis. Contudo, não há como obscurecer que, no âmbito da saúde suplementar, não são ofertados planos de saúde à sociedade estritamente vinculados ao custo-efetividade de procedimentos médicos, mormente diante da dificuldade de realizar estudos conclusivos sobre as diversas intervenções terapêuticas que possam ser disponíveis em determinadas situações clínicas. A esse título, registre-se que é vasto o entendimento jurisprudencial nas diversas instâncias do Judiciário Brasileiro, considerando abusiva a restrição ao emprego de stents, farmacológicos ou não, ficando a escolha a critério do médico assistente, mesmo naqueles planos que contêm cláusulas restritivas ao uso de órteses e próteses.

Tal contexto tem influído de forma acentuadamente negativa na relação médico-paciente, pois constitui, ad limine, interferência na autonomia do médico quando da escolha do melhor tratamento para seu paciente. É também inegável que as transformações experimentadas pela medicina, no decorrer do século passado, alçaram-na à inequívoca condição de verdadeira ciência, ainda que matizada pelo aspecto não menos imanente de que continue a ser também arte das mais expressivas entre as atividades do ser humano. Hoje, particularmente no caso da cardiologia, existe robusta fundamentação embasada em real miríade de evidências científicas oriundas de estudos aleatorizados multicêntricos, isolados ou em metanálises, para extensa gama de condutas aplicáveis a diversificados cenários clínicos. Nesse sentido, em sintonia com o disposto no Código de Ética Médica, é possível se estabelecer limites adequados para a prática médica a ser reconhecidamente aceita e requerida nesse diploma normativo. As diretrizes societárias representam ainda considerável avanço no auxílio ao médico, aos agentes financiadores da saúde e, notadamente, aos pacientes, no sentido de se encontrar a melhor decisão a ser adotada e individualizada para cada paciente.

Lamentavelmente, o foco da discussão sobre stents farmacológicos no Brasil tem se centralizado em questões dissociadas da melhor prática médica. Desviouse para agenda de litígios e incompreensões, que contrapõem médicos e operadoras de planos de saúde, em especial suas auditorias. Os conflitos de interesses que permeiam a relação entre médicos e indústria de dispositivos também avolumam e potenciam o cenário das divergências. Diante desse contexto, os pacientes ficam vulneráveis às regras impostas por uma avassaladora economia de mercado. Registre-se, contudo, que, a despeito de todos esses óbices, o número total de stents farmacológicos implantados no País cresceu progressivamente desde sua disponibilização inicial em 2001. Assim, dos procedimentos registrados na Central Nacional de Intervenções Cardiovasculares (CENIC), apenas 5\% utilizaram stents farmacológicos no biênio 2002-2003, porcentual que se elevou a $14 \%$ no biênio seguinte ${ }^{34}$. Conforme previsível, à luz das considerações vertidas neste artigo, mesmo no âmbito das indicações não contempladas no bulário os stents farmacológicos têm sido empregados no Brasil, ainda que as taxas seguramente muito inferiores ao desejável. Disso é exemplo o que ocorreu no contexto das angioplastias primárias, analisadas com os procedimentos relatados à CENIC durante o biênio 2006-2007, nos quais os stents farmacológicos foram implantados em apenas 4,1\% de 4.876 pacientes com infarto agudo do miocárdio ${ }^{35}$.

As operadoras de planos de saúde, atuando naquela senda de observância a estritas regras de economia de mercado, passam a atuar como agentes intermediários entre médicos e pacientes, imiscuindo-se no já desvirtuado ato médico que outrora, nas inspiradas palavras de Miguel Reale, se resumia na relação entre uma confiança (a do cliente) e uma consciência $^{36}$ (a do médico). Como afirma Ruy Rosado de Aguiar Jr.: "As circunstâncias hoje estão mudadas. As relações sociais massificaram-se, distanciando o médico do seu paciente. A própria denominação dos sujeitos da relação foi alterada, passando para usuário e pres- 
Lopes MACQ, et al. Conflitos Éticos e Judiciais no Emprego dos Stents Farmacológicos no Brasil. Análise das Principais Controvérsias para Incorporação dessa Tecnologia nos Sistemas de Saúde Público e Privado no País. Rev Bras Cardiol Invas. 2009 ;17(1):117-32.

tador de serviços, tudo visto sob a ótica de uma sociedade de consumo, cada vez mais consciente de seus direitos, reais ou fictícios, e mais exigente quanto aos resultados ${ }^{37 \prime \prime}$.

Por fim, ressalte-se que, se de um lado, no âmbito da saúde suplementar, tem sido a tônica do Judiciário a concessão dos stents farmacológicos, a situação no que respeita ao sistema de saúde pública é diversa, pois não se configuram, com a mesma frequência, demandas judiciais correlatas, embora haja ampla fundamentação para que ocorressem. Em parte, tal fato se deve a certa leniência da classe médica em prescrever tais dispositivos, mesmo sob circunstâncias em que estão formalmente indicados. Destaque-se, nesse contexto, que o dever de aconselhamento aos pacientes, seguramente, encontra-se inadimplido. Seria plausível, então, pleitear-se que fossem impetradas ações civis públicas, a fim de fazer com que o Estado reconhecesse a necessidade de arcar com tais tratamentos e implementasse, por meio do Poder Executivo, política pública específica para tal intuito, munindo-se para isso das devidas providências legais, aqui incluída a indispensável dotação orçamentária de recursos.

\section{CONFLITO DE INTERESSES}

Luiz Antonio Gubolino e Luiz Alberto Mattos foram palestrantes em eventos ou atividades patrocinadas pelas seguintes indústrias: Abbott, Boston, Cordis Biotronik e Medtronic. Luiz Alberto Mattos participou de estudos clínicos ou experimentais subvencionados pelas seguintes indústrias: Cordis Biotronik, Medtronic e Biosensors. Os demais autores declararam inexistência de conflito de interesses.

\section{REFERÊNCIAS BIBLIOGRÁFICAS}

1. Gruentzig AR, Myler RK, Hanna ES, Turina MI. Coronary transluminal angioplasty. Circulation. 1977;56(Supl 3):III-84.

2. Serruys PW, de Jaegere P, Kiemeneij F, Macaya C, Rutsch W, Heyndrickx G, et al. A comparison of balloon-expandablestent implantation with balloon angioplasty in patients with coronary artery disease. Benestent Study Group. N Engl J Med. 1994;331(8):489-95.

3. Kastrati A, Schömig A, Elezi S, Schühlen $H$, Dirschinger J, Hadamitzky M, et al. Predictive factors of restenosis after coronary stent placement. J Am Coll Cardiol. 1997;30(6): 1428-36.

4. Serruys PW, Kay IP, Disco C, Deshpande NV, de Feyter PJ. Periprocedural quantitative coronary angiography after PalmazSchatz stent implantation predicts the restenosis rate at six months: results of a meta-analysis of the Belgian Netherlands Stent study (BENESTENT) I, BENESTENT II Pilot, BENESTENT II and MUSIC (Multicenter Ultrasound Stent In Coronaries) trials. J Am Coll Cardiol. 1999;34(4):1067-74.

5. Morice MC, Serruys PW, Sousa JE, Fajadet J, Ban Hayashi E, Perin $M$, et al. A randomized comparison of a sirolimuseluting stent with a standard stent for coronary revascularization. N Engl J Med. 2002;346(23):1773-80.

6. Serruys PW, Ong AT, van Herwerden LA, Sousa JE, Jatene A, Bonnier JJ, et al. Five-year outcomes after coronary stenting versus bypass surgery for the treatment of multivessel disease: the final analysis of the Arterial Revascularization Therapies Study (ARTS) randomized trial. J Am Coll Cardiol. 2005; 46(4):575-81.

7. Mercado N, Wijns $W$, Serruys PW, Sigwart U, Flather MD, Stables $\mathrm{RH}$, et al. One-year outcomes of coronary artery bypass graft surgery versus percutaneous coronary intervention with multiple stenting for multisystem disease: a metaanalysis of individual patient data from randomized clinical trials. J Thorac Cardiovasc Surg. 2005;130(2):512-9.

8. Sousa JE, Costa MA, Abizaid A, Feres F, Seixas AC, Tanajura $\mathrm{LF}$, et al. Four-year angiographic and intravascular ultrasound follow-up of patients treated with sirolimus-eluting stents. Circulation. 2005;111(18):2326-9.

9. Marroquin OC, Selzer F, Mulukutla SR, Williams DO, Vlachos HA, Wilensky RL, et al. A comparison of bare metal and drug-eluting stents for off-label indications. $N$ Engl J Med. 2008;358(4):342-52.

10. Polanczyk CA, Wainstein MV, Ribeiro JP. Custo-efetividade dos stents recobertos com rapamicina em procedimentos percutâneos coronarianos no Brasil. Arq Bras Cardiol. 2007; 88(4):464-74.

11. Araújo DV, Lima VC, Ferraz MB. Análise de impacto do stent farmacológico no orçamento do Sistema Único de Saúde. Arq Bras Cardiol. 2007;88(4):458-63.

12. Kfouri Neto M. Responsabilidade civil do médico. 4a ed. São Paulo: Editora Revista dos Tribunais; 2001.

13. Mattos LA, Lemos Neto PA, Rassi A Jr, Marin-Neto JA, Sousa AGMR, Devito FS, et al. Diretrizes da Sociedade Brasileira de Cardiologia - Intervenção Coronária Percutânea e Métodos Adjuntos em Diagnóstico em Cardiologia Intervencionista (II Edição - 2008). Arq Bras Cardiol. 2008;91(6 Supl 1):1-58.

14. Moses JW, Leon MB, Popma JJ, Fitzgerald PJ, Holmes DR, O'Shaughnessy C, et al. Sirolimus-eluting stents versus standard stents in patients with stenosis in a native coronary artery. N Engl J Med. 2003;349(14):1315-23.

15. Stettler C, Wandel S, Allemann S, Kastrati A, Morice MC, Schömig A, et al. Outcomes associated with drug-eluting and bare-metal stents: a collaborative network meta-analysis. Lancet. 2007;370(9591):937-48.

16. Mauri L, Silbaugh TS, Garg P, Wolf RE, Zelevinsky K, Lovett A, et al. Drug-eluting or bare-metal stents for acute myocardial infarction. N Engl J Med. 2008;359(13):1330-42.

17. Rothwell PM. External validity of randomised controlled trials: "To whom do the results of this trial apply?". Lancet. 2005;365(9453):82-93.

18. McFadden EP, Stabile E, Regar E, Cheneau E, Ong AT, Kinnaird $\mathrm{T}$, et al. Late thrombosis in drug-eluting coronary stents after discontinuation of antiplatelet therapy. Lancet. 2004;364(9444): 1519-21.

19. Serruys PW, Daemen J. Are drug-eluting stents associated with a higher rate of late thrombosis than bare metal stents? Late stent thrombosis: a nuisance in both bare metal and drug-eluting stents. Circulation. 2007;115(11):1433-9.

20. http://www.fda.gov/ohrms/dockets/ac/06/minutes/20064253m1-quicksum.pdf. Acesso em 6 de fevereiro de 2009.

21. Grines CL, Bonow RO, Casey DE Jr, Gardner TJ, Lockhart PB, Moliterno DJ, et al. Prevention of premature discontinuation of dual antiplatelet therapy in patients with coronary artery stents: a science advisory from the American Heart Association, American College of Cardiology, Society for Cardiovascular Angiography and Interventions, American College of Surgeons, and American Dental Association, with representation from the American College of Physicians. J Am Coll Cardiol. 2007;49(6):734-9. 
22. Spaulding C, Daemen J, Boersma E, Cutlip DE, Serruys PW. A pooled analysis of data comparing sirolimus-eluting stents with bare-metal stents. N Engl J Med. 2007;356(10):989-97.

23. Garcia B. Instituições de direito penal. 3a ed. São Paulo: Max Limonad; 1956. Vol. I. Tomo II. p.259.

24. Dibra A, Kastrati A, Alfonso F, Seyfarth M, Pérez-Vizcayno MJ, Mehilli J, et al. Effectiveness of drug-eluting stents in patients with bare-metal in-stent restenosis: meta-analysis of randomized trials. J Am Coll Cardiol. 2007;49(5):616-23.

25. Hoye A, lakovou I, Ge L, van Mieghem CA, Ong AT, Cosgrave J, et al. Long-term outcomes after stenting of bifurcation lesions with the "crush" technique: predictors of an adverse outcome. J Am Coll Cardiol. 2006;47(10):1949-58.

26. Ardissino D, Cavallini C, Bramucci E, Indolfi C, Marzocchi A, Manari A, et al. Sirolimus-eluting vs uncoated stents for prevention of restenosis in small coronary arteries: a randomized trial. JAMA. 2004;292(22):2727-34.

27. Gubolino LA, Mangione JA, Silva SS, Marin-Neto JA, Lopes MACQ, Salvadori Junior D, et al. Diretrizes da Sociedade Brasileira de Cardiologia sobre Qualidade Profissional e Institucional, Centro de Treinamento e Certificação Profissional em Hemodinâmica e Cardiologia Intervencionista (II Edição - 2008). Rev Bras Cardiol Invas. 2008;16(Supl 3):8-32.

28. http://usuarios.cultura.com.br/jmrezende/ Acesso em 6 de fevereiro de 2009.

29. Trindade IS. Stent é realmente um epônimo? Rev Bras Cardiol Invas. 2003;11(4):64-6.
30. Häberle P. Hermenêutica constitucional - a sociedade aberta dos intérpretes da constituição: constituição para e procedimental da constituição. Tradução Mendes GF. Porto Alegre: Sérgio Antônio Fabris; 1997.

31. Reddy KS, Yusuf S. Emerging epidemic of cardiovascular disease in developing countries. Circulation. 1998;97(6):596-601.

32. Sanderson JE, Mayosi B, Yusuf S, Reddy S, Hu S, Chen Z, et al. Global burden of cardiovascular disease. Heart. 2007; 93(10):1175.

33. Rassi A Jr. Análise econômica dos stents coronarianos farmacológicos no Brasil: para todos ou para poucos pacientes? Arq Bras Cardiol. 2007;88(4):376-7.

34. Cardoso CO, Quadros AS, Mattos LA, Gottschall CA, Sarmento-Leite RE, Marin-Neto JA. Perfil de uso dos stents farmacológicos no Brasil: dados da Central Nacional de Intervenções Cardiovasculares (CENIC). Arq Bras Cardiol. 2007; 89(6):356-61.

35. DeVito FS, Marin-Neto JA, Mattos LA. Análise comparativa da intervenção coronária percutânea com stents farmacológicos versus stents não-farmacológicos na vigência de infarto do miocárdio com supradesnivelamento do segmento ST: dados do Registro Brasileiro CENIC. Rev Bras Cardiol Invas. 2008; 16(4):456-62.

36. Reale M. Código de ética médica. São Paulo: Editora Revista dos Tribunais; 1977. Vol. 503. p.47.

37. Teixeira SF. Direito \& medicina: aspectos jurídicos da medicina. Belo Horizonte: Del Rey; 2000. 